\title{
FAILURE OF TANNIC ACID TO INHIBIT DIGESTION OR REDUCE DIGESTIBILITY OF PLANT PROTEIN IN GUT FLUIDS OF INSECT HERBIVORES: Implications for Theories of Plant Defense
}

\author{
J.S. MARTIN, ${ }^{1}$ M.M. MARTIN, ${ }^{1}$ and E.A. BERNAYS ${ }^{2}$ \\ 'Division of Biological Sciences, University of Michigan \\ Ann Arbor, Michigan 48109 \\ ${ }^{2}$ Division of Biological Control \\ University of California at Berkeley \\ 1050 San Pablo Avenue, Albany, California 94706
}

(Received February 3, 1986; accepted April 16, 1986)

\begin{abstract}
The rate of hydrolysis of the abundant foliar protein, ribulose-1,5bisphosphate carboxylase/oxygenase (RuBPC), in enzymatically active gut fluid of Manduca sexta larvae is very rapid and is unaffected by the presence of tannic acid, even when tannic acid is present in the incubation mixture in amounts in excess of the amount of RuBPC. When this protein is dissolved in the denatured gut fluids of $M$. sexta larvae or Schistocerca gregaria nymphs, large amounts of tannic acid must be added to bring about the precipitation of significant quantities of protein. The ability of insect gut fluid to prevent the formation of insoluble tannin-protein complexes is due to the presence of surfactants. On the basis of our results and a review of the findings of other investigators, we argue that there is no evidence that tannins reduce the nutritional value of an insect's food by inhibiting digestive enzymes or by reducing the digestibility of ingested proteins and, further, that the failure of tannins to interfere with digestion is readily explained on the basis of well-documented characteristics of the digestive systems of herbivorous insects. In challenging the currently popular notion that tannins are digestibility-reducing substances, we do not challenge the general utility of either the apparency theory or resource availability theory of plant defense. In debating the merits of these two analyses of plant-herbivore interactions, however, the demise of tannins as all-purpose, dose-dependent, digestibilityreducing defensive substances must be taken into account.
\end{abstract}

Key Words-Tannins, digestibility-reducing substances, surfactants, detergency, herbivory, chemical defense, allelochemics, Manduca sexta, Lepidoptera, Sphingidae, Schistocerca gregaria, Orthoptera, Acrididae. 


\section{INTRODUCTION}

Ingested tannins interfere with the normal growth and development of many foliage-feeding insects, and this class of allelochemicals has been accorded an important role in protecting vascular plants from herbivory (Feeny, 1976; Rhoades and Cates, 1976; Swain, 1979; Coley et al., 1985). Tannins are known to be protein precipitants (Van Sumere et al., 1975; Hagerman and Butler, 1981; McManus et al., 1983), and it has been proposed that they might interfere with protein digestion in an herbivore's gut by binding proteolytic enzymes or ingested proteins (Feeny, 1976; Rhoades and Cates, 1976). Since the growth of many herbivores is nitrogen limited (Mattson, 1980), any interference with protein digestion could have a severe negative impact on fitness. While there is evidence that tannins act as digestion-inhibiting substances in certain species of vertebrates, possibly by interfering with the growth and metabolism of rumen microorganisms (Waterman et al., 1980, 1984), to date there has been no experimental demonstration that tannins ever act as digestibility-reducing or digestion-inhibiting substances in any herbivorous insect species (Bernays, 1981; Martin and Martin, 1984; Martin et al., 1985). The adverse effects that dietary tannins have on the growth and development of tannin-sensitive insects appear to be due instead to the properties of these polyphenols as feeding deterrents (Klocke and Chan, 1982; Reese et al., 1982; Manuwoto et al., 1985; Manuwoto and Scriber, 1986) and toxins (Berenbaum, 1984; Bernays et al., 1980; Manuwoto et al., 1985; Manuwoto and Scriber, 1986; Steinly and Berenbaum, 1986).

Several characteristics of the digestive systems of insects have been identified which counter the potential anti-digestive properties of tannins. It has been proposed that high gut alkalinity is an antitannin adaptation in lepidopteran larvae (Feeny, 1970; Berenbaum, 1980) and that detergency is a widespread characteristic of insect gut fluids that prevents tannins from precipitating ingested proteins (Martin and Martin, 1984; Martin et al., 1985). In addition, some species of acridids possess digestive $\beta$-glucosidases that are able to degrade hydrolyzable tannins and peritrophic membranes that adsorb tannins and remove them from the gut milieu (Bernays, 1981).

In this study we have assessed the capacity of tannic acid to act as a digestion-inhibiting or digestibility-reducing substance in the tobacco hornworm, Manduca sexta, and the locust, Schistocerca gregaria. $M$. sexta larvae do not normally consume tannin-containing foliage and would not be expected to have evolved specific adaptations to counter the potential adverse effects of tannins, while $S$. gregaria feeds on the foliage of many plant species containing tannins and is quite tolerant of these polyphenols (Bernays, 1981). We have explored the effect of added tannic acid on the rate of hydrolysis of the abundant foliar protein, ribulose-1,5-bisphosphate carboxylase/oxygenase (RuBPC), in enzy- 
matically active gut fluid of $M$. sexta at $\mathrm{pH} 10.2-10.6$ and have measured the amount of RuBPC precipitated from the denatured gut fluids of $M$. sexta and $S$. gregaria at $\mathrm{pH}$ values near neutrality by various amounts of tannic acid. We have conducted these experiments at tannin-protein ratios ranging from zero to values in excess of unity, a range which probably includes the values typical of most natural vegetation. Finally, we have performed experiments to establish which components of the gut fluid are responsible for its ability to prevent the formation of insoluble complexes between tannic acid and RuBPC. Our results do not support the idea that tannins are digestion-inhibiting or digestibilityreducing substances in insects.

\section{METHODS AND MATERIALS}

Culturing of Insects. Fifth-instar $M$. sexta larvae were reared from eggs on an artificial agar-based diet (Yamamoto, 1969) supplemented with wheat-germ oil $(2.99 \mathrm{~g} / 1000 \mathrm{~g}$ diet $)$. Alternatively, larvae were reared on artificial diet through the third instar, at which time they were transferred to tomato plants and allowed to feed through the fifth instar on tomato foliage. Late-instar larvae were also collected from tomato plants growing in a tomato field in Washtenaw County, Michigan. Fifth-instar $S$. gregaria nymphs were raised in crowds on bran and wheat seedlings at The Centre for Overseas Pest Research, London, U.K.

Determination of Minimum Gut Passage Time. Ten fifth-instar larvae, weighing between 3.272 and $5.004 \mathrm{~g}$ (the size range used as a source of gut fluid), were placed in Petri dishes containing a cube of artificial diet amended with a small amount of finely divided charcoal. After feeding for $30 \mathrm{~min}$, the larvae were transferred back to diet lacking charcoal. Frass pellets were collected every half hour for the next $10 \mathrm{hr}$ and were inspected visually for the presence of charcoal particles. In separate experiments, it was established that the rates of feeding and pellet production by larvae that had ingested charcoalamended diet were no different from the rates for larvae that had not fed on the charcoal-amended diet.

Collection of Gut Fluid. Gut fluid was collected from actively feeding fifthinstar $M$. sexta larvae. After making an incision encircling the body, the intact midgut was exposed by gently pulling the two halves of the body apart. The exposed midgut was rinsed with distilled water, blotted dry, and slit longitudinally, allowing the contents to flow into a centrifuge tube chilled in an ice bath. Following centrifugation $\left(12,000 \mathrm{~g}, 10 \mathrm{~min}, 5^{\circ} \mathrm{C}\right)$, the supernatant fluid was either frozen and stored at $-16^{\circ} \mathrm{C}$ or denatured by heating at $100^{\circ} \mathrm{C}$ for $10 \mathrm{~min}$, centrifuged as before, lyophilized, and stored dry at $-16^{\circ} \mathrm{C}$. There was no significant loss of proteolytic activity in active gut fluid stored in a 
frozen state at $-16^{\circ} \mathrm{C}$ even after several months. Gut fluid from 3- to 5-dayold ( $\pm 12 \mathrm{hr}$ ) fifth-instar nymphs of $S$. gregaria was obtained both by inducing regurgitation through handling and by expressing gut contents from a small hole cut at the foregut-midgut junction of the excised gut. Gut fluid was removed with $100-\mu 1$ capillary tubes and collected in $2-\mathrm{ml}$ portions in chilled vials, denatured by heating at $100^{\circ} \mathrm{C}$ for $15 \mathrm{~min}$, lyophilized, and air-mailed from London, U.K., to Ann Arbor, Michigan. Upon arrival in Ann Arbor, the lyophilized material in each vial was redissolved by adding water $(3 \mathrm{ml})$. The mixture was centrifuged $\left(12,000 \mathrm{~g}, 10 \mathrm{~min}, 20^{\circ} \mathrm{C}\right)$, the supernatant solutions from all of the vials were combined, and the pooled preparation was lyophilized and stored dry at $-16^{\circ} \mathrm{C}$.

Fractionation of Gut Fluid. Nine volumes of $95 \%$ ethanol were added to one volume of gut fluid, and the mixture was allowed to stand for $18 \mathrm{hr}$ at $5^{\circ} \mathrm{C}$. Following centrifugation $\left(12,000 \mathrm{~g}, 10 \mathrm{~min}, 20^{\circ} \mathrm{C}\right)$, the supernatant solution was concentrated almost to dryness on a rotary concentrator at reduced pressure. The concentrated solution was then lyophilized and stored dry at $-16^{\circ} \mathrm{C}$. This fraction, which contains all solutes not precipitated by ethanol, was designed fraction $\mathrm{A}$. The precipitate from the ethanol treatment was placed under a gentle stream of nitrogen to remove traces of ethanol, dissolved in water (two times the volume of the original gut fluid), and filtered through a YM-10 membrane (Amicon Corp. Danvers, MA). Both filtrate and residue were lyophilized and stored dry at $-16^{\circ} \mathrm{C}$. The filtrate, which contained solutes precipitated by ethanol having molecular weights less than $10 \mathrm{kD}$, was designated fraction $\mathrm{B}$. The residue, which contained solutes precipitated by ethanol having molecular weights greater than $10 \mathrm{kD}$, was designated fraction $\mathrm{C}$.

$p H$ Measurements. Measurements of $\mathrm{pH}$ were made on freshly collected $M$. sexta gut fluid or rehydrated $S$. gregaria gut fluid using a combination $\mathrm{pH}$ microelectrode (Microelectrodes, Inc.).

Surface Tension. Surface tension was measured using the horizontal thickwalled capillary apparatus of Ferguson (1943). Surfactant concentration, in multiples of the critical micelle concentration (CMC), was determined by measuring the surface tensions of a series of dilutions of the test sample, and noting the dilution at which there was an abrupt increase in surface tension (Martin and Martin, 1984). The CMC is the concentration at which there is a transition between the surfactant in the free, unassociated state and the micellar state. The diluent was $160 \mathrm{mM} \mathrm{KCl}-3 \mathrm{mM} \mathrm{NaCl}$, chosen to maintain ionic conditions comparable to those typical in insect midgut fluids (Giordana and Sacchi, 1978).

Precipitation of RuBPC by Tannic Acid. Full-strength denatured gut fluid was reconstituted from lyophilized gut fluid powder by adding water (one third of the volume of the gut fluid from which the powder was originally derived) and an equal volume of $0.3 \mathrm{M}$ PIPES buffer [piperazine- $N, N^{\prime}$-bis-(2-ethanesulfonic acid)], $\mathrm{pH} 6.8$, and adjusting the $\mathrm{pH}$ of the mixture to 6.8 by the 
dropwise addition of either $\mathrm{HCl}$ or $\mathrm{KOH}$. Preparations of gut fluid from larvae from the agar-based artificial diet contained suspended lipid-like particles, which were removed by filtration through Celite. Water was added to the solution or filtrate to bring the final volume to that of the gut fluid from which the powder was derived.

Solutions containing the separate gut fluid fractions were prepared from the lyophilized powders by adding water (one sixth of the volume of the gut fluid from which the powder was originally derived) and an equal volume of $0.3 \mathrm{M}$ PIPES buffer, $\mathrm{pH} 6.8$, adjusting the $\mathrm{pH}$ to 6.8 by the dropwise addition of either $\mathrm{HCl}$ or $\mathrm{KOH}$, and finally adding water to bring the volume to one half the original volume of the gut fluid from which the fraction was derived. This solution, which was twice as concentrated as gut fluid, was then combined with either an equal volume of $0.1 \mathrm{M}$ PIPES, $\mathrm{pH} 6.8$, or with an equal volume of a solution of a different gut fluid fraction prepared in the same manner. A solution containing all three gut fluid fractions was prepared by combining solutions of fractions A and B with a weighed quantity of lyophilized fraction C.

RuBPC (Sigma R-8000, Lot 82F-7340) was added to reconstituted denatured gut fluid or solutions of the gut fluid fractions ( $2 \mathrm{mg} \mathrm{RuBPC} / \mathrm{ml})$, and the mixture was allowed to stand for $18 \mathrm{hr}$ at $5^{\circ} \mathrm{C}$, after which it was shaken for $10 \mathrm{~min}$ at room temperature and centrifuged $\left(14,500 \mathrm{~g}, 10 \mathrm{~min}, 20^{\circ} \mathrm{C}\right)$. The amount of RuBPC in solution was then determined using the assay procedure described below. Virtually all of the RuBPC dissolved in the $M$. sexta gut fluid, while only about three fourths dissolved in the $S$. gregaria gut fluid, perhaps because of the much higher concentrations of solutes already present in the $S$. gregaria fluid (see Table 3). To $250 \mu \mathrm{l}$ of this solution was added, with vortexing, $25 \mu \mathrm{l}$ of a freshly prepared solution of tannic acid (Sigma T-0125, lot 40F-0253) in 0.1 M PIPES, pH 6.8. After $10 \mathrm{~min}$, the mixture was centrifuged $\left(14,500 \mathrm{~g}, 10 \mathrm{~min}, 20^{\circ} \mathrm{C}\right)$, the supernatant solution was decanted, and the pellet was rinsed carefully with $0.1 \mathrm{M}$ PIPES, $\mathrm{pH} 6.8$. The pellet was dissolved in $0.60 \mathrm{ml}$ of a solution of $1 \%$ SDS in $0.05 \mathrm{M}$ Tris, $\mathrm{pH} 7.5$, and protein was precipitated by adding $0.15 \mathrm{ml}$ of $90 \%$ trichloroacetic acid. The amount of protein precipitated was determined using the assay described below.

Proteolysis in Active M. sexta Gut Fluid. A mixture, prepared by adding $100 \mu \mathrm{l}$ of a solution of RuBPC $(10.8-14.0 \mathrm{mg} / \mathrm{ml})$ in $1.0 \mathrm{M}$ CAPS [3-(cyclohexylamino)propanesulfonic acid], $\mathrm{pH} 10.5$, to $1 \mathrm{ml}$ of active gut fluid, was incubated at $24^{\circ} \mathrm{C}$. Duplicate aliquots $(25 \mu \mathrm{l})$, removed after 5 and $15 \mathrm{~min}$, were added to $0.15 \mathrm{ml}$ of $90 \%$ trichloroacetic acid, and the amount of protein precipitated was determined using the assay procedure described below. When tannic acid was included in an incubation, it was added to the gut fluid immediately prior to the addition of the RuBPC solution. When the amount of tannic acid in the incubation mixture was $1.5 \mathrm{mg} / \mathrm{ml}$, it was added as the dry solid; when it was $0.14 \mathrm{mg} / \mathrm{ml}$, it was added in $10 \mu \mathrm{l}$ of an aqueous solution. In 
separate experiments it was established that proteins present originally in the gut fluid sample were stable and did not undergo autolysis or hydrolysis during incubation. Thus, the decrease in protein content during incubation was due to hydrolysis of the added RuBPC.

Protein Assay. Protein was measured using the method of Schaffner and Weissmann (1973) as adapted by Martin et al. (1985). Protein precipitated from a test solution by the addition of trichloroacetic acid was absorbed on a nitrocellulose membrane $(0.45 \mu \mathrm{m})$ and stained with Amido black 10B. After removing excess unbound Amido black 10B, protein-bound dye was eluted and absorbance at $630 \mathrm{~nm}$ was determined. Absorbance at $630 \mathrm{~nm}$ resulting from substances other than RuBPC was determined from RuBPC-free blanks, and this value, which was always small, was subtracted from the observed absorbance of the test sample in order to give the absorbance due to RuBPC. Absorbance at $630 \mathrm{~nm}$ due to RuBPC was converted into micrograms of protein by the use of a calibration curve constructed from dilutions of a stock solution of RuBPC.

\section{RESULTS}

Rate of Passage of Food through Guts of Fifth-Instar M. sexta Larvae. When fifth-instar larvae were allowed to feed for 30 minutes on artificial diet to which finely divided charcoal had been added and then transferred back to charcoal-free diet, the average time interval between the initiation of feeding on the charcoal-containing diet and the appearance of charcoal in a fecal pellet was $2.6 \mathrm{hr}$ (standard error 0.16 ). The last fecal pellet containing detectable charcoal particles was produced after $8.45 \mathrm{hr}$ (standard error 0.31). Although this experiment does not permit an accurate calculation of the average length of time that a food particle is in contact with midgut digestive enzymes, it does clearly indicate that the time is measured in hours, not minutes.

Digestion of RuBPC in Active M. sexta Gut Fluid. The hydrolysis of RuBPC in undiluted enzymatically active $M$. sexta gut fluid at pH 10.2-10.6 is very rapid, whether tannic acid is present or not (Table 1). After only $5 \mathrm{~min}$, digestion was $60-87 \%$ complete. Our attempts to assess the effects of added tannic acid on the extent of proteolysis after $5 \mathrm{~min}$, when proteolysis was still in progress, were only partially successful, owing to the variability in our measurements of the amount of unhydrolyzed protein present in a solution in which protein content is changing rapidly. In the runs initially containing 1.08 and $1.18 \mathrm{mg} / \mathrm{ml}$ of RuBPC, the inclusion of tannic acid in the incubation mixture did not result in a reduction in the amount of hydrolysis after $5 \mathrm{~min}$, while in the run initially containing $1.36 \mathrm{mg} / \mathrm{ml}$ of RuBPC, the inclusion of $1.50 \mathrm{mg}$ / $\mathrm{ml}$ of tannic acid resulted in a $30 \%$ decrease in the amount of RuBPC hydro- 
Table 1. Effect of Tannic Acid (TA) on Hydrolysis of RuBPC in Enzymatically Active Gut Fluid from FifTh InStar $M$. sexta Larvae Fed Tomato Leaves during Last Two Instars ${ }^{a}$

\begin{tabular}{|c|c|c|c|}
\hline \multicolumn{2}{|c|}{ Incubation mixture } & \multicolumn{2}{|c|}{$\begin{array}{c}\mathrm{RuBPC} \text { digested }[\mathrm{mg} / \mathrm{ml}(\% \text { of } \\
\text { original })]\end{array}$} \\
\hline $\operatorname{RuBPC}(\mathrm{mg} / \mathrm{ml})$ & $\mathrm{TA}(\mathrm{mg} / \mathrm{ml})$ & $5 \mathrm{~min}$ & $15 \mathrm{~min}$ \\
\hline 1.08 & 0.00 & $0.86(80)$ & $1.07(99)$ \\
\hline 1.08 & 0.14 & $0.90(83)$ & $1.11(103)$ \\
\hline 1.18 & 0.00 & $0.80(68)$ & $1.22(103)$ \\
\hline 1.18 & 1.50 & $0.83(70)$ & $1.16(98)$ \\
\hline 1.36 & 0.00 & $1.18(87)$ & $1.30(96)$ \\
\hline 1.36 & 1.50 & $0.82(60)$ & $1.30(96)$ \\
\hline
\end{tabular}

${ }^{a}$ The incubation mixture had a volume of $1.1 \mathrm{ml}$ and a $\mathrm{pH}$ of $10.2-10.6$. Values are the averages of duplicate determinations.

lyzed after $5 \mathrm{~min}$. After $15 \mathrm{~min}$, however, digestion was complete in all cases, even when tannic acid was present in the incubation mixture in excess of the RuBPC present. Since food is in contact with midgut digestive enzymes for a period far in excess of $15 \mathrm{~min}$, it is clear that there is no significant interference with the digestion of RuBPC by tannic acid in the undiluted active gut fluid of M. sexta larvae.

Precipitation of RuBPC from Denatured M. sexta Gut Fluid or Solutions of Gut Fluid Components by Tannic Acid. Much larger quantities of tannic acid are required to bring about precipitation of an insoluble RuBPC-tannic acid complex from denatured $M$. sexta gut fluid adjusted to a $\mathrm{pH}$ of 6.7-6.9 than are required to precipitate this protein from an aqueous salt solution buffered at the same $\mathrm{pH}$ (Table 2). While $50 \mu \mathrm{g}$ of tannic acid precipitates 465 out of $525 \mu \mathrm{g}$ of RuBPC from a salt solution at pH 6.8, this amount of tannic acid precipitates only 7 out of $500 \mu \mathrm{g}$ of this protein when it is dissolved in the gut fluid of larvae reared on an artificial diet. The effectiveness of the gut fluid as a solvent for RuBPC in the presence of tannic acid depends upon the dietary history of the larvae. Much more tannic acid is required to precipitate significant amounts of RuBPC from the gut fluids of larvae switched from artificial diet to tomato leaves during their final two instars or larvae which had been collected from tomato plants growing in a cultivated field and which had presumably fed on tomato foliage during their entire larval stage (Table 2).

Using a straightforward procedure involving precipitation with ethanol and ultrafiltration through a membrane with a nominal molecular weight cutoff of $10 \mathrm{kD}$, the gut fluid was separated into three fractions (Table 3). Fraction $\mathrm{A}$ contains all solutes not precipitated by ethanol, fraction B contains solutes pre- 
Table 2. Amounts of RuBPC Precipitated by Tannic Acid (TA) from Aqueous Buffer and Denatured Gut Fluids from Fifth-Instar $M$. sexta LaRvae and $S$. gregaria Nymphs ${ }^{a}$

\begin{tabular}{|c|c|c|c|c|c|}
\hline & \multirow{2}{*}{$\begin{array}{l}\text { RuBPC in incubation } \\
\text { mixture }(\mu \mathrm{g})\end{array}$} & \multicolumn{4}{|c|}{ RuBPC precipitated $(\mu \mathrm{g})$ by } \\
\hline & & $50 \mu \mathrm{g} \mathrm{TA}$ & $75 \mu \mathrm{g}$ TA & $200 \mu \mathrm{g}$ TA & $300 \mu \mathrm{g} \mathrm{TA}$ \\
\hline $\begin{array}{l}\text { 0.1 M PIPES buffer, pH 6.8, } 160 \\
\mathrm{mM} \mathrm{KCl}, 3 \mathrm{mM} \mathrm{NaCl}\end{array}$ & 525 & $465 \pm 3$ & ND & ND & ND \\
\hline $\begin{array}{l}\text { Gut fluid from } M \text {. sexta larvae reared } \\
\text { entirely on artificial diet }\end{array}$ & 500 & $\begin{array}{c}7 \pm 2 \\
{[3]}\end{array}$ & $\begin{array}{c}35 \pm 9 \\
{[4]}\end{array}$ & $\underset{[3]}{414 \pm 4}$ & $\begin{array}{c}480 \pm 6 \\
{[3]}\end{array}$ \\
\hline $\begin{array}{l}\text { Gut fluid from } M \text {. sexta larvae } \\
\text { switched from artificial diet to } \\
\text { tomato leaves for last two instars }\end{array}$ & 500 & ND & ND & $11 \pm 2$ & $\underset{[3]}{92 \pm 8}$ \\
\hline $\begin{array}{l}\text { Gut fluid from } M . \text { sexta larvae } \\
\text { collected from a tomato field }\end{array}$ & 500 & ND & ND & ND & $\begin{array}{l}8 \pm 0 \\
{[2]}\end{array}$ \\
\hline $\begin{array}{l}\text { Gut fluid from } S . \text { gregaria nymphs } \\
\text { reared on wheat and bran seedlings }\end{array}$ & 360 & ND & ND & $11 \pm 5$ & $\begin{array}{c}87 \pm 4 \\
{[5]}\end{array}$ \\
\hline
\end{tabular}

${ }^{a}$ The incubation mixture had a volume of $275 \mu \mathrm{l}$ and a pH of 6.7-6.9. Values are $\tilde{X} \pm$ SEM for the number of replicates given in brackets. The small number of replicates precludes the calculation of statistical significance. Values of SEM are included only to provide an indication of the low variance between replicates. ND, not determined.

cipitated by ethanol with molecular weights less than $10 \mathrm{kD}$, and fraction $\mathrm{C}$ contains solutes precipitated by ethanol with molecular weights greater than 10 $\mathrm{kD}$. Experiments testing the effects of fractions $\mathrm{A}, \mathrm{B}$, and $\mathrm{C}$ on the precipitation of RuBPC by tannic acid implicate surfactants as the components responsible for the effectiveness of gut fluid in preventing the precipitation of protein by tannic acid.

Fraction B contains low-molecular-weight solutes, including inorganic salts, which favor the formation of insoluble tannin-protein complexes (Martin et al., 1985). It is to be expected, therefore, that relatively small quantities of tannic acid would be effective in precipitating protein from a solution of fraction $\mathrm{B}$, and indeed, most of the RuBPC is precipitated by only 50 or $75 \mu \mathrm{g}$ of tannic acid when the source of fraction $B$ is gut fluid from diet-fed larvae (Table 4). Thus a solution of fraction B from diet-fed animals differs little from a simple buffered salt solution in terms of its properties as a solvent for tannin-protein complexes.

It is interesting to note that more tannic acid is required to precipitate the RuBPC dissolved in a solution containing fraction B from $M$. sexta larvae fed leaves during their last two instars than one containing fraction $B$ from larvae reared exclusively on artificial diet (Table 4), suggesting that the composition of this fraction depends upon the larval diet. Insufficient material was available for a test of the properties of fraction B from field-collected larvae. 


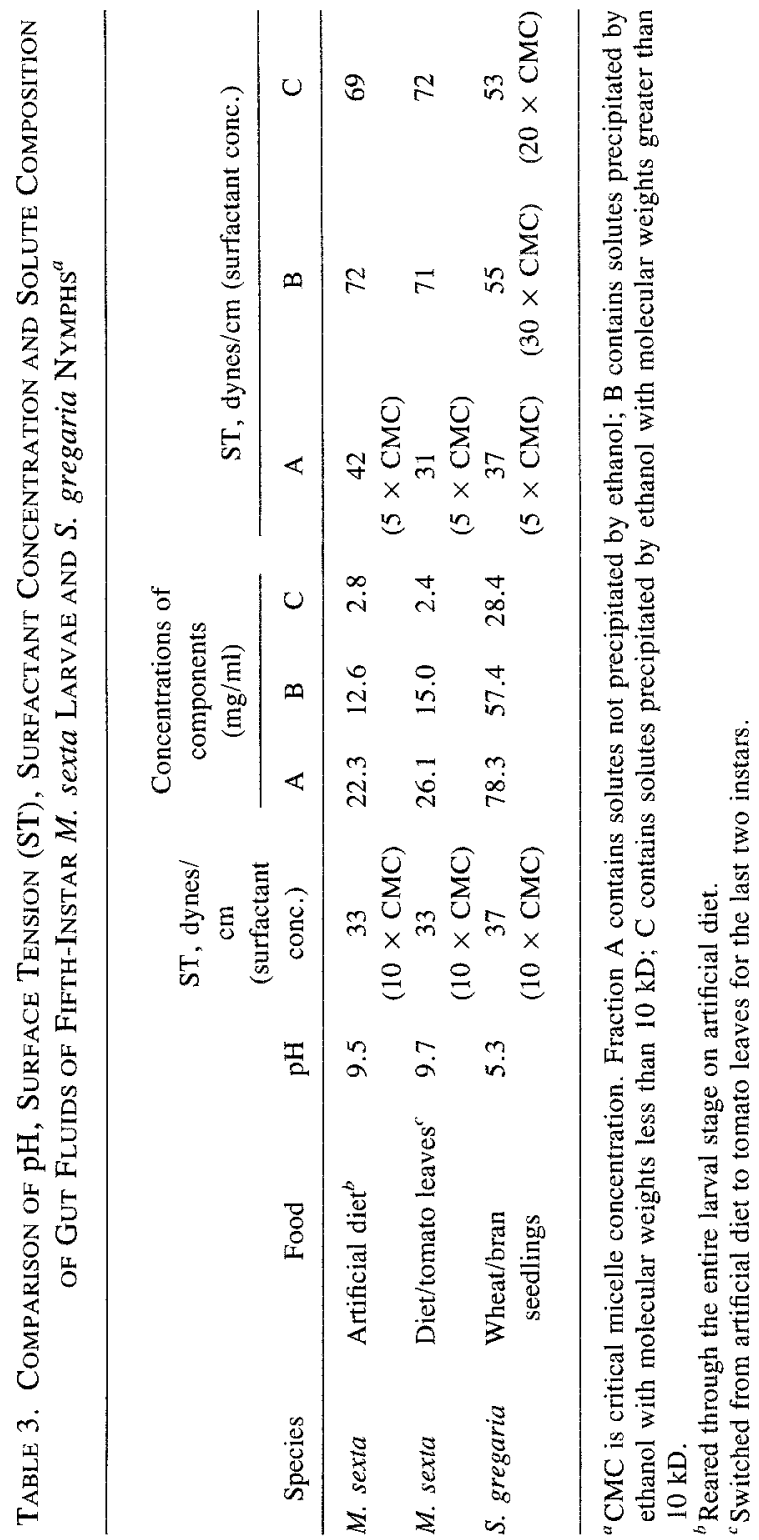


Table 4. Amounts of RuBPC Precipitated by Tannic Acid (TA) From Solutions Containing Various Components of Gut Fluids from FIfTH-Instar $M$. sexta LARVAE AND $S$. gregaria NyMPHS $^{a}$

\begin{tabular}{|c|c|c|c|c|c|c|c|c|}
\hline \multirow[b]{2}{*}{ Species } & \multirow[b]{2}{*}{ Food } & \multicolumn{3}{|c|}{$\begin{array}{c}\text { Components } \\
\text { present in } \\
\text { incubation } \\
\text { mixture }\end{array}$} & \multicolumn{4}{|c|}{ RuBPC precipitated $(\mu \mathrm{g})$ by } \\
\hline & & A & B & $\mathrm{C}$ & $50 \mu \mathrm{g} \mathrm{TA}$ & $75 \mu \mathrm{g}$ TA & $200 \mu \mathrm{g}$ TA & $300 \mu \mathrm{g}$ TA \\
\hline M. sexta & Artificial diet ${ }^{n}$ & - & + & - & $314 \pm 8$ & $451 \pm 38$ & ND & ND \\
\hline M. sexta & Artificial diet $^{a}$ & + & + & - & $26 \pm 1$ & $52 \pm 7$ & ND & ND \\
\hline M. sexta & Artificial diet ${ }^{a}$ & + & + & + & $10 \pm 1$ & $35 \pm 4$ & ND & ND \\
\hline M. sexta & Diet/tomato leaves ${ }^{b}$ & - & + & - & ND & $75 \pm 12$ & $434 \pm 35$ & $493 \pm 7$ \\
\hline M. sexta & Diet/tomato leaves ${ }^{b}$ & + & + & - & ND & $5 \pm 1$ & $13 \pm 1$ & $81 \pm 27$ \\
\hline M. sexta & Tomato leaves $^{c}$ & + & + & - & ND & $\mathrm{ND}$ & ND & $8 \pm 2$ \\
\hline S. gregaria & Wheat/bran seedlings & - & + & - & ND & $37 \pm 5$ & $293 \pm 34$ & $447 \pm 55$ \\
\hline S. gregaria & Wheat/bran seedlings & + & + & - & ND & $12 \pm 4$ & $133 \pm 6$ & $309 \pm 9$ \\
\hline S. gregaria & Wheat/bran seedlings & + & + & + & ND & ND & $24 \pm 5$ & $122 \pm 8$ \\
\hline
\end{tabular}

${ }^{a}$ The incubation mixture had a volume of $275 \mu \mathrm{l}$, a pH of 6.8-7.0, and contained $500 \mu \mathrm{g}$ of RuBPC (except in the experiment in which all three components from $S$. gregaria gut fluid were recombined, in which case $300 \mu \mathrm{g}$ of RuBPC were present). Values are $\bar{X} \pm$ SEM for three replicates. The small number of replicates precludes the calculation of statistical significance. Values of SEM are included only to provide an indication of the low variance between replicates. The contents of fractions A, B and C are described in the heading for Table 3. ND, not determined.

${ }^{b}$ Reared through the entire larval stage on artificial diet.

${ }^{c}$ Switched from artificial diet to tomato leaves for the last two instars.

${ }^{d}$ Collected from tomato plants in a tomato field.

Fraction $\mathrm{A}$ is the only fraction from either diet- or leaf-fed $M$. sexta larvae which contains surfactants, as indicated by surface-tension measurements (Table 3). Since water has a surface tension of 72 dynes $/ \mathrm{cm}$, the values of 69-72 dynes $/ \mathrm{cm}$ for solutions of fractions $\mathrm{B}$ and $\mathrm{C}$ indicate that these fractions do not contain significant concentrations of surface-active materials. However, the values of 31 and 42 dynes $/ \mathrm{cm}$ for solutions of fraction A from diet- and leaf-fed larvae, respectively, indicate the presence of surfactants in those fractions. The amount of RuBPC precipitated by 50 and $75 \mu \mathrm{g}$ of tannic acid is reduced to 26 and $52 \mu \mathrm{g}$, respectively, when the solution contains fraction A, the surfaceactive fraction, in addition to fraction $B$. In fact, the combination of fractions $A$ and $B$ is nearly as effective as the original gut fluid or reconstituted gut fluid (fractions $\mathrm{A}+\mathrm{B}+\mathrm{C}$ ) from the diet-fed insects in preventing the precipitation of dissolved RuBPC by tannic acid (Tables 2 and 4). Likewise, when RuBPC is dissolved in a solution containing both fractions A and B from the gut fluid and leaf-fed larvae, as much tannic acid must be added to precipitate this protein as is required to effect precipitation from the original gut fluid. 
Precipitation of RuBPC from Denatured S. gregaria Gut Fluid or Solutions of Gut Fluid Components by Tannic Acid. The gut fluid of $S$. gregaria nymphs reared on bran and wheat seedlings, adjusted to $\mathrm{pH} 6.7-6.9$, is as effective at preventing the precipitation of RuBPC by tannic acid as the gut fluid of $M$. sexta larvae fed tomato leaves during their last two instars (Table 2). However, the results of experiments testing the effects of the individual fractions from the locust gut fluid were somewhat different from those using the fractions from the hornworm gut fluid (Table 4). With materials from both $M$. sexta and S. gregaria, the precipitation of RuBPC was brought about by a relatively small amount of tannic acid when it was dissolved in a solution of fraction $\mathrm{B}$, the salt-containing fraction. However, in contrast to the results obtained with the $M$. sexta materials, the combination of fractions A and B from $S$. gregaria did not give a solution as effective at preventing the precipitation of protein by tannic acid as the original gut fluid. Only when all three of the gut fluid fractions from $S$. gregaria were combined was the resulting solution as effective as the original gut fluid.

In marked contrast to the results obtained when $M$. sexta gut fluid was subjected to fractionation, the surface-active components of $S$. gregaria gut fluid were not cleanly separated into a single fraction (Table 3 ). Solutions of all three fractions had surface tensions well below the value for water, indicating that all three contained surface-active constituents. It is also evident from the concentrations of dissolved solids in the various fractions that locust gut fluid is a much more concentrated solution than hornworm gut fluid. Perhaps the failure of the fractionation procedure to result in a clean separation of surfactants into a single fraction is simply a consequence of the much higher solute content of $S$. gregaria gut fluid $(164 \mathrm{mg} / \mathrm{ml}$ ) than $M$. sexta gut fluid ( 37 and 44 $\mathrm{mg} / \mathrm{ml}$ ). In any event, the observation that all fractions containing surfactants must be recombined in order to obtain a solution with properties comparable to those of the original gut fluid is consistent with the suggestion that surfactants are responsible for the ability of the gut fluid to prevent the precipitation of RuBPC by tannic acid.

\section{DISCUSSION}

Three mechanisms have been proposed by which tannins might interfere with digestion in an insect herbivore: (1) by inhibiting the herbivore's digestive enzymes, (2) by inhibiting the metabolic activities of symbiotic microorganisms that contribute to digestion, and (3) by reducing the digestibility of ingested nutrients.

The suggestion that tannins might inhibit an herbivore's digestive proteinases is a very plausible one, supported by well-documented examples of the inhibition of a variety of enzymes by tannins. Tannins have been shown to 
inhibit $\alpha$-amylase (Gadal and Boudet, 1965), pectinase (Bell et al., 1962), cellulase (Bell et al., 1962; Mandels and Reese, 1965), and $\beta$-glucosidase (Goldstein and Swain, 1965; Goldstein and Spencer, 1985). The inhibition of proteolysis by tannins has also been observed, but it has not been possible to determine whether this effect is a consequence of inhibition of the proteinases or of binding to substrates (Feeny, 1969; Rhoades, 1977). It is interesting that Mole and Waterman (1985) have recently demonstrated that under certain conditions tannins can stimulate the tryptic hydrolysis of proteins. In all of the studies in which tannins have been reported to inhibit enzyme-catalyzed processes, very dilute preparations of the enzymes have been used, and conditions have been employed which are very different from those that prevail in an insect's gut. In this study we have shown that in undiluted gut fluid from $M$. sexta larvae, the hydrolysis of RuBPC occurs with extraordinary rapidity and is not inhibited by tannic acid, even when the incubation mixture contains as much or more tannic acid as it contains RuBPC. Of course, it is still possible that tannins might inhibit the proteinases of insect species with less active enzymes, less alkaline midgut, or lower concentrations of detergents in their gut fluids, but to date there is no evidence that they do. Until direct evidence for such inhibition is provided, we maintain that there is no justification for believing that tannins interfere with protein digestion by inhibiting digestive proteinases in any insect herbivore.

Tannins have been observed to inhibit rumen microbes (Waterman et al., 1980,1984 ), suggesting the possibility that polyphenols might interfere with digestive processes mediated by symbiotic microorganisms. While this mode of action is a possibility in insects, to date it has not been demonstrated, and there is no basis for believing that it is of widespread importance in herbivorous species. It is most unlikely to be a factor in lepidopteran or acridid herbivores, since gut microbes are not thought to play a significant role in digestion in these groups.

The suggestion that tannins might interfere with protein utilization by forming indigestible complexes with ingested protein is also a very plausible one, considering the extensively documented capacity of tannins to act as protein precipitants. However, in this study we have shown that the abundant leaf protein, RuBPC, is not readily precipitated from the gut fluids of $M$. sexta and $S$. gregaria. We conducted our experiments at $\mathrm{pH} 6.7-6.9$, a $\mathrm{pH}$ which is very favorable for the formation of an insoluble complex between tannic acid and this protein (Martin and Martin, 1983). Only when enough tannic acid is added to the mixture to produce a ratio of tannic acid to protein close to unity is a significant portion of the protein precipitated from the gut fluids of hornworm larvae that had been feeding on tomato foliage or locust nymphs that had been feeding on bran and wheat seedlings.

In this study we have shown that the capacity of gut fluid to counter the 
effects of tannic acid on the digestion and precipitation of RuBPC manifests itself at tannic acid-RuBPC ratios of $1.3: 1.0$ and $0.4-0.6: 1.0$, respectively. Unfortunately, tannin-protein ratios in foliage are known accurately for very few plant species. In the mature foliage of the pedunculate oak, Quercus robur, tannins were quantified accurately by actual isolation, and the tannin-protein ratio was found to be 0.34 (Feeny, 1970). The more common practice in assessing tannin content in foliage is to use functional group assays, such as the Folin-Denis assay, the proanthocyanidin assay, and the catechin assay, and translate the data into "tannin equivalents." The accuracy and utility of such estimates of tannin content are highly suspect (Martin and Martin, 1982). While the proanthocyanidin and catechin assays may provide rough indications of the levels of condensed tannins, the Folin-Denis assay provides no measure whatsoever of total tannin content. Indeed, there is no satisfactory functional group assay for "total tannin," and none of the functional group assays correlate with protein-binding capacity. With these caveats in mind, we note that in only 15 of the 102 species of forest vegetation surveyed by Oates et al. (1980), Waterman et al. (1980), and Coley (1983) did assays for proanthocyanidins or catechins suggest that the condensed tannin-protein ratio might be greater than unity.

In this study and our earlier ones (Martin and Martin, 1984; Martin et al., 1985), we implicated surfactants as the constituents of insect gut fluids that prevent the precipitation of proteins by tannic acid or pin oak tannins. Mole and Waterman (1985) have also demonstrated that surfactants can prevent tannic acid or quebracho tannin from inhibiting the tryptic hydrolysis of bovine serum albumin. In our earlier study (Martin and Martin, 1984), we restricted our attention to a fraction of $M$. sexta gut fluid corresponding to fraction A of this study. Since the preparation of fraction A results in the separation of surfaceactive substances from the inorganic salts present in the gut fluid, and since inorganic salts enhance the precipitation of proteins by tannins (Martin et al., 1985), it was possible that our earlier study overemphasized the potential for surfactants to interfere with the precipitation of proteins by tannins. The present study has ruled out that possibility. We have found that unfractionated gut fluid is extremely effective in preventing the precipitation of RuBPC by tannic acid and that a solution prepared by recombining gut fluid surfactants and gut fluid salts is as effective in this capacity as the unfractionated gut fluid.

We were surprised to find that the capacity of the gut fluid of $M$. sexta larvae to counter the protein-precipitating capacity of tannins is affected by the nature of the larval diet. The most effective gut fluid was from larvae that had consumed tomato foliage throughout larval life, while the least effective was from larvae that had been reared exclusively on an artificial diet. Gut fluid from larvae that had been switched from an artificial diet to tomato foliage for their last two instars was intermediate in its properties. These differences cannot be attributed to differences in detergency of the gut fluids of larvae with different 
dietary histories. Surface-tension measurements of the unfractionated gut fluid and fraction A from diet-fed and leaf-fed larvae indicate no differences in surfactant concentrations (Table 3). Rather, the differences seem to be due to differences in the capacity of fraction B to cause precipitation of RuBPC by tannic acid. Perhaps the gut fluids of diet-fed insects have higher concentrations of inorganic salts, especially alkali metal salts, which are particularly effective in bringing about the precipitation of tannin-protein complexes (Martin et al., 1985).

In $M$. sexta midgut fluid, which normally has a $\mathrm{pH}$ of 9.5 or higher, both high alkalinity and detergency interfere with the formation of insoluble tanninprotein complexes. In $S$. gregaria, however, high alkalinity cannot be a factor. Evans and Payne (1964) reported a pH of 5.5 in the crop of this species, where a significant amount of digestion occurs, and a $\mathrm{pH}$ range of $6.2-7.0$ in the midgut. The $S$. gregaria digestive fluid used in this study, which was primarily crop fluid mixed with some midgut fluid, had a $\mathrm{pH}$ of 5.3. RuBPC is readily precipitated from an aqueous salt solution in the $\mathrm{pH}$ range 5.5-7.0 (Martin and Martin, 1983). The observation that $S$. gregaria gut fluid interferes with the formation of tannin-protein complexes at $\mathrm{pH}$ 6.7-6.9 emphasizes the significance of surfactants in countering the protein-precipitating capacity of tannins in insect herbivores with gut fluids which are neutral or slightly acidic.

This study, in conjunction with other studies which have failed to produce any evidence that dietary tannins reduce digestive efficiency in any insect (Bernays et al., 1980; Klocke and Chan, 1982; Reese et al., 1982; Manuwoto et al., 1985; Manuwoto and Scriber, 1986), adds further support to our contention that tannins do not deserve the status they have been accorded as general, allpurpose, digestibility-reducing substances. It is now abundantly clear that the digestive systems of insects possess a number of attributes that effectively counter the potential protein-precipitating capacity of tannins. At least two of these attributes, alkalinity and detergency, occur widely in insects, in species both with and without an evolutionary history of exposure to tannins, indicating that these characteristics have not necessarily evolved specificially as antitannin adaptations (Martin and Martin, 1984; Martin et al., 1985). In order to ensure that our position not be misinterpreted, we wish to emphasize that we are not proposing that tannins are innocuous chemicals that pose no problems to insect herbivores. There is no question that tannins can act as toxins (Berenbaum, 1984; Bernays et al., 1980; Manuwoto et al., 1985; Manuwoto and Scriber, 1986; Steinly and Berenbaum, 1986) and feeding deterrents (Bernays, 1981; Klocke and Chan, 1982; Reese et al., 1982; Manuwoto et al., 1985) to nonadapted insects. We are only arguing that there is no evidence that tannins reduce the nutritional value of an insect's food by inhibiting digestive enzymes or by reducing the digestibility of ingested proteins, and further that the failure of tannins to interfere with digestion is readily explained on the basis of welldocumented characteristics of the digestive systems of herbivorous insects. 
Furthermore, we emphasize that in challenging the currently popular notion that tannins are digestibility-reducing substances, we are not challenging the general utility of either the apparency theory (Feeny, 1976; Rhoades and Cates, 1976) or the resource availability theory (Coley et al., 1985) of plantherbivore interactions. According to both of these theories, low nutrient quality can reduce herbivory by imposing slower growth rates on herbivores, thereby subjecting them to higher mortality from parasitism, predation, and other factors during an extended juvenile period. The only points that we dispute are the assertions that polyphenols make a crucial contribution to low nutritive quality by interfering with digestion and that counteradaptation to the presence of polyphenols is unusually difficult. The demise of tannins as all-purpose digestibility-reducing substances requires that the advocates of these theories of plant defense find other explanations for the reduced nutrient quality of the foliage of "apparent" or inherently slow-growing species.

Acknowledgments - This research was supported by a grant from the National Science Foundation (PCM-8203537). We thank Randy Mercer for determining the minimum gut passage time in $M$. sexta larvae; Barbara Joos and Hugh McGuinness for $M$. sexta larvae; and Judy Bronstein, David Karowe, and Heidi Van't Hof for valuable criticisms.

\section{REFERENCES}

Bell, T.A., Etchells, J.L., Williams, C.F., and Porter, W.L. 1962. Inhibition of pectinase and cellulase by certain plants. Bot. Gaz. 123:220-223.

Berenbaum, M. 1980. Adaptive significance of midgut pH in larval Lepidoptera. Am. Nat. $115: 138-146$.

Berenbaum, M. 1984. Effects of tannin ingestion on two species of papilionid caterpillars. Entomol. Exp. Appl. 34:245-250.

Bernays, E.A. 1981. Plant tannins and insect herbivores: An appraisal. Ecol. Entomol. 6:353360.

Bernays, E.A., Chamberlain, D.J., and McCarthy, P. 1980. The differential effects of ingested tannic acid on different species of Acridoidea. Entomol. Exp. Appl. 28:158-166.

COLEY, P.D. 1983. Herbivory and defensive characteristics of tree species in a lowland tropical forest. Ecol. Monogr. 53:209-232.

Coley, P.D., BRYANT, J.P., and Chapin, S. 1985. Resource availability and plant antiherbivore defense. Science 230:895-899.

Evans, W.A.L., and PAYNE, D.W. 1964. Carbohydrases of the alimentary tract of the desert locust, Schistocerca gregaria Forsk. J. Insect Physiol. 10:657-674.

FEENY, P.P. 1969. Inhibitory effect of oak leaf tannins on the hydrolysis of proteins by trypsin. Phytochemistry 8:2119-2126.

FEENY, P.P. 1970. Seasonal changes in oak leaf tannins and nutrients as a cause of spring feeding by winter moth caterpillars. Ecology 51:561-581.

FeEny, P. 1976. Plant apparency and chemical defense. Recent Adv. Phytochem. 10:1-40.

FERGUSON, A. 1943. Surface tension and its measurement. Endeavor 2:34-38.

GADAl, P., and Boudet, A. 1965. Sur l'inhibition des enzymes par les tannins des feuilles de Quercus sessilis Ehrh. Inhibition de la $\alpha$-amylase. C. R. Acad. Sci. Paris 260:4252-4255.

GIORDANA, B., and SACCHI, F. 1978. Cellular ionic concentrations in the midgut of two larvae of Lepidoptera in vivo and in vitro. Comp. Biochem. Physiol. 59A:17-20. 
Goldstein, J.L., and Swain, T. 1965. The inhibition of enzymes by tannins. Phytochemistry $4: 185-192$.

GOLDSTEIN, W.S., and SPENCER, K.C. 1985. Inhibition of cyanogenesis by tannins. J. Chem. Ecol. 11:847-858.

HAGERMAN, A.E., and ButLER, L.G. 1981. The specificity of proanthocyanidin-protein interactions. J. Biol. Chem. 256:4494-4497.

KLOCKE, J.A., and ChAN, B.G. 1982. Effects of cotton condensed tannins on feeding and digestion in the cotton pest, Heliothis zea. J. Insect Physiol. 28:911-915.

Mandels, M., and Reese, E.T. 1965. Inhibition of cellulase. Annu. Rev. Phytopathol. 3:85-102.

MANuwoto, S., and SCRIBER, J.M. 1986. Effects of hydrolyzable and condensed tannin on growth and development of two species of polyphagous lepidoptera: Spodoptera eridania and Callosamia promethea. Oecologia. 69:225-230.

Manuwoto, S., Scriber, J.M., HSia, M.T., and Sunarjo, P. 1985. Antibiosis/antixenosis in tulip tree and quaking aspen leaves against the polyphagous southern armyworm, Spodoptera eridania. Oecologia 67:1-7.

MARTIN, J.S., and MARTIN, M.M. 1982. Tannin assays in ecological studies: Lack of correlation between phenolics, proanthocyanidins and protein-precipitating constituents in mature foliage of six oak species. Oecologia 54:205-211.

Martin, J.S. and Martin, M.M. 1983. Tannin assays in ecological studies: Precipitation of ribulose-1,5-bisphosphate carboxylase/oxygenase by tannic acid, quebracho, and oak foliage extracts. J. Chem. Ecol. 9:285-294.

MARTIN, M.M., and MARTIN, J.S. 1984. Surfactants: Their role in preventing the precipitation of proteins by tannins in insect guts. Oecologia 61:342-345.

MaRTin, M.M., RockHOLM, D.C., and MARTIN, J.S. 1985. Effects of surfactants, pH, and certain cations on precipitation of proteins by tannins. J. Chem. Ecol. 11:485-494.

Mattson, W.J. 1980. Herbivory in relation to plant nitrogen content. Annu. Rev. Ecol. Syst. 11:119-161.

MCMAnus, J., LILley, T.H., and Haslam, E. 1983. Plant polyphenols and their association with proteins, pp. 123-137, in P.A. Hedin (ed.). Plant Resistance to Insects. ACS Symposium Series 208. American Chemical Society, Washington, D.C.

Mole, S., and Waterman, P.G. 1985. Stimulatory effects of tannins and cholic acid on tryptic hydrolysis of proteins: Ecological implications. J. Chem. Ecol. 11:1323-1332.

OATES, J.F., Waterman, P.G., and Choo, G.M. 1980. Food selection by the South Indian leaf monkey, Presbytis johnii, in relation to leaf chemistry. Oecologia 45:45-56.

REESE, J.C., CHAN, B.G., and WAISS, A.C., JR. 1982. Effects of cotton condensed tannin, maysin (com) and pinitol (soybeans) on Heliothis zea growth and development. J. Chem. Ecol. 8:14291436.

RHOADES, D.F. 1977. The antiherbivore chemistry of Larrea, pp. 135-175, in T.J. Mabry, J.H. Hunziker, and D.R. DiFeo (eds.). Creosote Bush: Biology and Chemistry of Larrea in New World Deserts. Hutchinson and Ross, Stroudsbourg, Pennsylvania.

RHOADES, D.F., and CATES, R.G. 1976. A general theory of plant antiherbivore chemistry. Recent Adv. Phytochem. 10:168-213.

SCHAFFNER, W., and WEISSMANN, C. 1973. A rapid, sensitive and specific method for the determination of protein in dilute solution. Anal. Biochem. 56:502-514.

Steinly, N., and Berenbaum, M. 1986. Histopathological effects of tannins on the midgut epithelium of Papilio polyxenes and Papilio glaucus. Entomol. Exp. Appl. 39:3-9.

SwaIN, T. 1979. Tannins and lignins, pp. 657-682, in G.A. Rosenthal and D.H. Janzen (eds.). Herbivores: Their Interaction with Secondary Plant Metabolites. Academic Press, New York.

Van Sumere, C.F., Albrecht, J., Dedonder, A., De Pooter, H., and Pe, I. 1975. Plant protein and phenolics, pp. 211-264, in J.B. Harbome and C.F. Van Sumere (eds.). The Chemistry and Biochemistry of Plant Proteins. Academic Press, New York. 
Waterman, P.G., Mbi, C.N., MCKey, D.B., and Gartlan, J.S. 1980. African rainforest vegetation and rumen microbes: phenolic compounds and nutrients as correlates of digestibility. Oecologia 47:22-33.

Waterman, P.G., Ross, J.A.M., and MCKEy, D.B. 1984. Factors affecting levels of some phenolic compounds, digestibility, and nitrogen content of the mature leaves of Barteria fistulosa (Passifloraceae). J. Chem. Ecol. 10:387-401.

YAMAMOTO, R.T. 1969. Mass rearing of the tobacco hornworm. II. Larval rearing and preparation. J. Econ. Entomol. 62:1427-1431. 